\title{
Preserving Authenticity in Virtual Heritage
}

\author{
Erik Champion \\ Curtin University, University of Western Australia, \\ Australian National University \\ erik.champion@curtin.edu.au
}

\begin{abstract}
This chapter examines why we wish to preserve heritage objects and practices via virtual heritage, and why the issue of authenticity is so important here but so seldom addressed. If we could give criteria to select and to create useful and even authentic-oriented virtual heritage projects, what would they be? Or are there methods and solutions out there waiting to be discovered?
\end{abstract}

\section{Why Aren't 3D Models Used, Wanted, or Archived?}

If virtual heritage is a preservation medium (and not just a communication medium), an immediate question might well be: why are virtual heritage projects worth saving? Are they worth saving? In the case of 3D and game environments, some have suggested even knowing what they are to be used for can be extremely unclear.

How to cite this book chapter:

Champion, E. 2021. Preserving Authenticity in Virtual Heritage. In: Champion, E. M. (ed.) Virtual Heritage: A Guide. Pp. 129-137. London: Ubiquity Press. DOI: https://doi.org /10.5334/bck.l. License: CC-BY-NC 


\section{Digital Heritage - The Vanishing Virtual}

Are they being saved? Digital Humanities is/are all around us, yet 3D models, especially 3D cultural heritage models, are seldom discussed as part of scholarly arguments (Di Benedetto et al. 2014; Huggett 2012), nor are they valued as research output, made accessible to the wider public (Talboom \& Underdown 2019), or generally evaluated for significance, engagement, or impact.

UNESCO's Charter on the Preservation of the Digital Heritage warned of the increasing risks to heritage (UNESCO 2009):

... the rapid obsolescence of the hardware and software which brings it to life, uncertainties about resources, responsibility and methods for maintenance and preservation, and the lack of supportive legislation.

According to Hal Thwaites (2013), '...digital heritage [is] disappearing faster than the real heritage' and there is urgent need for greater accessibility, consistent interface design, global infrastructure, archival standards, and ongoing curation.

\section{Formats and Platforms}

Although there have been useful recent surveys on 3D model formats (Fernie 2020) and an upcoming survey on digitalisation quality (Iliofotou 2021), we still lack sufficient surveys on required features and procedures for 3D file formats, their relative dependability, accessibility, playability, graceful degradeability, scalability, and range of device-suitability, even if their long-term cost and proprietary status can be determined. The problem is not through a lack of 3D formats, there are over 140 3D formats (McHenry \& Bajcsy 2008), but they don't always allow for ease of use across various applications (Neamţu et al. 2014; Tsiafaki \& Michailidou 2015).

Another immediate problem is access. In previous work, with Dr Hafizur Rahaman (Champion \& Rahaman 2020), we reviewed virtual heritage platform hosting solutions. None offered all of the basic interactive features we thought would be most useful for virtual heritage. The commercial Sketchfab website offered the most features and hosted the most models, with a variety of import and export formats. Common platform formats were FBX (Autodesk), glTF/ GLB, DAE (Collada), and OBJ, but there was also USDZ (a 3D file format that displays $3 \mathrm{D}$ and $\mathrm{AR}$ content on iOS devices), and application-native formats (such as UNITY). U3D and VRM/X3D did not seem to be popular formats on these platforms. IIIF 3D is an interesting 3D format but is still under development and discussion.

We have also surveyed the availability of 3D models and related media (Champion \& Rahaman 2019) in virtual heritage conference presentations. From a group of 1483 conference papers over the period of 2012 to 2017, we 
selected 264 of the total papers published in VSMM, CAA, CIPA, EuroMed, and Digital Heritage Congress. Only 17.9\% referred to and contained images of $3 \mathrm{D}$ assets or 3D digital models. Only nine papers contained accessible 3D assets or 3D models. Nineteen articles contained external web links to 3D models but not a single link worked on the final day of our survey: 1 September 2018.

UNESCO (UNESCO 2016) provides several criteria to ensure the preservation of documentary heritage (including multimedia), reflected in its Memory of the World program (https://en.unesco.org/programme/mow/). A document itself 'is preservable and usually moveable ... [and] ... content may comprise signs or codes (such as text), images (still or moving) and sounds, which can be copied or migrated.' UNESCO states documentary heritage 'should be permanently accessible and re-usable by all without hindrance ... with due respect to and recognition of cultural mores and practicalities' and suggests that every country (state) '... should develop training and capacity-building schemes as appropriate to ensure the identification, preservation and access to documentary heritage training.'

\section{Use and Reuse}

To fulfil these objectives, UNESCO's Guarding Against Loss Of Heritage states we must build cooperation between all relevant public and private sectors, develop training and research, and encourage research organizations to preserve research data. One extra ingredient is needed; building on the FAIR Principles (https://www.go-fair.org/fair-principles/), ideally the project provides not just Findability, Accessibility, and Interoperability, but also the Reuse of digital assets.

Even academic reuse is uncommon. Although there have been virtual heritage conferences such as Virtual Systems and Multimedia, academic proceedings do not host the $3 \mathrm{D}$ models. There is an increasing number of academic journals providing an online display of 3D models, but they are not archives. They don't easily allow for maintenance and upgrading of the components.

Is the whole issue of $3 \mathrm{D}$ model preservation just too difficult? Is it really outside the scope or capacity of major players in the GLAM (galleries, libraries, archives, and museum) sector, or are these $3 \mathrm{D}$ models just not engaging to the public? Although the London Charter (Denard 2016) and various UNESCO Charters (UNESCO 2009, 2015) advocate the use of paradata and measures to counter technical obsolescence and physical decay, one major element is missing. Without doubt, we need to preserve and integrate $3 \mathrm{D} /$ multimedia; provide access and record the ownership of models, sites, and paradata; develop suitable guidelines and shared procedures; collate and distribute standardized evaluation data; and incorporate data tracking audience engagement and feedback. But we are still sidestepping a more fundamental challenge: the user experience. 
We also need to develop incentives - incentives for developers to provide showcases; ongoing funding through critical mass; use, reuse, and critical feedback in teaching; delivering to a wider audience; providing prizes, awards, or other recognition for technical collaborators; long-term depository citation and dynamic linking; modification of creative commons specifically for 3D heritage models, components, and sites; and providing a variety of level of data, access, or components.

There are research consortiums that handle their own online and archival functions, such as Europeana (Ubik \& Kubišta 2017) and the Smithsonian Institute (with their X3D beta), but academic research collaborations such as ARIADNE, 3D Icons, CARARE, and EU Epoch relied on regular research grants to continue or transferred their tools and case studies to their partners. They can provide expert and scholarly information on these models and sites. However, they are not geared towards use and reuse, streamlined and shareable across a variety of platforms with a standardized interface. Sketchfab (https://sketchfab.com) is one, and the Smithsonian (Daher 2020) and CYARK now use it.

Commercial online hosting solutions like Sketchfab are designed for presentation rather than for preservation and don't require scientific overview (Statham 2019). Conversely, for traditional libraries and museums, digital archives are relatively new and not particularly suited for 3D models. The GLAM sector lacks the requisite financial resources let alone enough time or adequate staffing. Unfortunately, virtual museums do not curate and preserve the models. And, according to Birrell (2019), many projects lack clear plans or even an understanding of who the end-users are (Bettivia 2016).

Communal groups, such as Micropasts (https://crowdsourced.micropasts .org/), by contrast, rely on volunteers. What they have in common is critical mass, features, and shareability. Micropasts has an added attraction, you can collaborate on archaeological problems and upload your own additional media.

Given virtual heritage implies the use and reuse of projects, I suggest there are at least six components required for preservation:

1. The dataset (2D, 3D, textures, sounds, scripts, etc.) of the virtual heritage itself.

2. The paradata that helped the research and development of the virtual heritage project.

3. The authorship, institutional links and accreditations, and teamwork.

4. The intentions of the authors.

5. The metadata and system structure and any relevant classification data.

6. Evaluation data (audience tracking, usability studies, audience engagement results, and an attempt to capture usable and useful audience experience and feedback). 


\section{Are Virtual Heritage Models Authentic?}

Must we slavishly copy, preserve objects in glass or cotton wool, and reproduce them with the most expensive equipment with the greatest possible digital file sizes? Every extra byte of a digital file requires hosting somewhere. Every computer server accessing the internet is powered, with a related environmental cost (Griffiths 2020). Despite improvements in the features, capacity, reliability, and precision of 3D formats, there is another, deeper underlying issue: what are these models preserving and what are they communicating to their audience?

The question of authenticity is not merely a question regarding the model, but also a question on the intentions of the modelmaker. Arguably the authentic is not only the saved object and the intentions of the preserver or modelmaker, but also the relationship people had with the object and the care shown. Care cannot be maintained behind glass even if artefacts left behind are as close as we can get to the past; they are inscrutable and mysterious ciphers to that culture. And the authentic is not merely the exterior, the similarity to the past, because we typically don't know the past. But the work and respect that went developing, maintaining, and handing down that cultural heritage object, belief, or performance is authentic. Can virtual heritage provide some sense of the relationship past people had to distant, remote, half-remembered, and disappearing places?

The user experience relies not only on technology and access to that technology but an experience of cultural heritage that is considered in some sense authentic and meaningful by the participant (Gilmore \& Pine 2007; Van Balen 2008).

In Authenticity: Depicting the Past in Historical Videogames, James Sweeting noted that authenticity could refer to "of undisputed origin of authorship", or in a weaker sense a "reliable, accurate representation" (Sweeting 2019). Authenticity could, however, mean more than authorship or accuracy. Could the virtual heritage experience also be viewed in terms of authenticity?

These considerations lead us to the following interpretations of 'authentic':

1. 'Authentic' might mean the results are seen by shareholders or experts as belonging to them or are accurate renditions of the original source materials.

2. 'Authentic' could be the interpretation by the original shareholders that the depictions or recreations are as per their trans-generational practices and beliefs.

3. Parallel to option 2, 'authentic' can refer to the authenticity of what is made, and how is it made (is the creation process true to tradition? Does it show care?).

4. Or 'authentic' could be an allusive but illusive relation to the experience, or expectation of character, by a shareholder or domain expert. 
We can focus these different strands of authenticity in terms of virtual heritage.

1. How an object is made.

2. Who owns or connects to the heritage depicted.

3. Who understands the culture from which an object is made or intangible heritage is performed or shared, or the experience itself.

These are all different but intertwined notions of authenticity. So, when virtual heritage is seen as authentic (if indeed, it is ever viewed through the lens of heritage), it could be seen as the safeguarding of ownership, identity, memory, craft, and art practices and so on. 'Authentic' could indicate ownership, of cultural affinity, but also authenticity in terms of where it is made or how it parallels experience. Authenticity leads to more questions, but when detected it can lead to increased engagement (Bunce 2016):

... visitors who perceived the rabbits as authentic were more likely to ask a question than those who judged them as inauthentic. Perceived authenticity also promoted more why questions.

Given the above and considering there are cultural distinctions in the understanding of 'authenticity', I suggest the goals of virtual heritage preservation are to preserve:

1. Projects and related data: the virtual heritage projects themselves.

2. Ideals: through raising awareness of the original materials and intangible assets or practices through the depiction and safeguarding of virtual reality and related digital media.

3. Specific generative and transmissive knowledge: The cultural knowledge, and current understanding of the specific cultural knowledge that gave the development and maintenance of cultural heritage meaning. For example, virtual heritage is not a collection of mere objects. It is the learning mechanism that transmits values of cultural heritage. Even with physical heritage sites, we preserve the material heritage to safeguard the related intangible heritage.

\section{Conclusion}

The Nara Charter (ICOMOS 1994) stipulates that authenticity is an essential component of cultural heritage. If we follow UNESCO's stipulation of the importance of cultural significance, what is worthy of preserving is the useful, the unique, the memorable, and the inspiring. So it seems we must aim to preserve 'the authentic', and this implies an objective yet universal truth. Interpretations differ, and resources are limited. A related thorny question for virtual heritage might be in determining the purpose of a virtual heritage model in 
terms of people's decisions, resources, and lives. The concept of authenticity has more recently been stretched and teased by theorists arguing over what heritage can be saved and lived with (Harrison 2013; Holtorf 2018).

How can digital heritage fulfil the noble aims of cultural heritage and the needs of society if it cannot even maintain, preserve, and sustain itself? There are too many divergent formats, no universal standards, missing case studies, and little agreement on protocols, standards, or parameters. Plus, the GLAM sector has increasingly limited resources (Münster 2019) to keep pace with changes in technology, hardware, applications, or social media trends. These problems are solvable but also depend on an improved understanding of authenticity, not only in terms of accuracy and precision and authorship but also in terms of illusive, perceived authenticity.

\section{References}

Bettivia, R S 2016 The power of imaginary users: Designated communities in the OAIS reference model. Proceedings of the Association for Information Science and Technology, 53(1): 1-9. DOI: https://doi.org/10.1002/pra2.2016 .14505301038

Birrell, L 2019 Leaving the stuff behind: One leader's approach to managing academic archives. Collections, 15(4): 240-252. DOI: https://doi.org /10.1177/1550190619888919

Bunce, L 2016 Appreciation of authenticity promotes curiosity: Implications for object-based learning in museums AU. Journal of Museum Education, 41(3): 230-239. DOI: https://doi.org/10.1080/10598650.2016.1193312

Champion, E and Rahaman, H 2019 3D digital heritage models as sustainable scholarly resources. Sustainability, 11(8): 2425.

Champion, E and Rahaman, H 2020 Survey of 3D Digital Heritage Repositories and Platforms. The Virtual Archaeology Review (VAR). DOI: https://doi .org/10.4995/var.2020.13226

Daher, N 2020 You Can Now Download 1,700 Free 3-D Cultural Heritage Models. Smithsonian Magazine. Retrieved from https://www.smithsonia nmag.com/smart-news/you-can-now-download-1700-free-3-d-models -cultural-heritage-artifacts-180974308/

Denard, H 2016 A new introduction to the London Charter. In: A. BentkowskaKafel, H. Denard, \& D. Baker (Eds.), Paradata and Transparency in Virtual Heritage (pp. 83-98). Farnham, Surrey, UK: Routledge.

Di Benedetto, M, Ponchio, F, Malomo, L, Callieri, M, Dellepiane, M, Cignoni, P, and Scopigno, R 2014 Web and mobile visualization for cultural heritage. In: 3D Research Challenges in Cultural Heritage (pp. 18-35): Springer.

Fernie, K 2020 3D Content in Europeana Task Force. Retrieved from https: //pro.europeana.eu/project/3d-content-in-europeana 
Gilmore, J H and Pine, B J 2007 Authenticity: What Consumers Really Want. Harvard Business Press.

Griffiths, S 2020 Why your internet habits are not as clean as you think. $B B C$ Future (Smart Guide to Climate Change). Retrieved from https://www.bbc .com/future/article/20200305-why-your-internet-habits-are-not-as-clean -as-you-think

Harrison, R 2013 Heritage: Critical Approaches. London, UK: Routledge.

Holtorf, C 2018 Conservation and heritage as future-making. Paper presented at the ICOMOS University Forum Workshop: 'A contemporary provocation: reconstructions as tools of future-making', Paris, France (13-15 May 2017).

Huggett, J 2012 Lost in information? Ways of knowing and modes of representation in e-archaeology. World Archaeology, 44(4): 538-552.

ICOMOS 1994 The Nara Document on Authenticity (1994). Retrieved from https://www.icomos.org/charters/nara-e.pdf

Iliofotou, E 2021, 12 January Survey on quality in digitisation of tangible cultural heritage. Retrieved from https://www.vi-mm.eu/2021/01/12/completed -survey-on-quality-in-digitisation-of-tangible-cultural-heritage/

McHenry, K and Bajcsy, P 2008 An overview of 3d data content, file formats and viewers. National Center for Supercomputing Applications, 1205: 22.

Münster, S 2019 Digital heritage as a scholarly field-Topics, researchers, and perspectives from a bibliometric point of view. Journal on Computing and Cultural Heritage (JOCCH), 12(3): 1-27.

Neamţu, C, Popescu, D, Mateescu, R, Suciu, L, and Hurgoiu, D 2014 About the quality and properties of digital artifacts. Mediterranean Archaeology and Archaeometry, 14(4): 55-64.

Statham, N 2019 Scientific rigour of online platforms for 3D visualization of heritage. Virtual Archaeology Review, 10(20): 1-16. DOI: https://doi.org /10.4995/var.2019.9715

Sweeting, J 2019 Authenticity: Depicting the past in historical videogames. In: Transtechnology Research Reader 2018 (pp. 62-83).

Talboom, L and Underdown, D 2019 'Access is What we are Preserving': But for Whom? Digital Preservation Coalition (OAIS Issues/Designated Community). Retrieved from https://www.dpconline.org/blog/access-what-we -are-preserving

Thwaites, H 2013 Digital heritage: What happens when we digitize everything? In: E. Ch'ng, V. Gaffney, \& H. Chapman (Eds.), Visual Heritage in the Digital Age (pp. 327-348). London: Springer.

Tsiafaki, D and Michailidou, N 2015 Benefits and problems through the application of 3D technologies in archaeology: Recording, visualisation, representation and reconstruction. Scientific Culture, 1(3): 37-45.

Ubik, S and Kubišta, J 2017 Scalable real-time sharing of 3D model visualizations for group collaboration. Paper presented at the International Conference on Cooperative Design, Visualization and Engineering. 
UNESCO 2009 Charter on the Preservation of the Digital Heritage 2003. Retrieved from Paris, France: https://unesdoc.unesco.org/ark:/48223/pf00 00179529.page $=2$

UNESCO 2015 Safeguarding the Memory of the World. Retrieved from UNESCO website: https://en.unesco.org/programme/mow/recommendation-docu mentary-heritage

UNESCO 2016 Recommendation concerning the Preservation of, and Access to, Documentary Heritage Including in Digital Form. Retrieved from Paris, France: https://unesdoc.unesco.org/ark:/48223/pf0000244675

Van Balen, K 2008 The Nara grid: An evaluation scheme based on the Nara document on authenticity. APT bulletin, 39(2/3): 39-45. 